\title{
Rea Vaya: South Africa's first bus \\ rapid transit system
}

AUTHORS:

Emmanuel Adewumi ${ }^{1}$

Dhiren Allopi'

\author{
AFFILIATION: \\ ${ }^{1}$ Department of Civil Engineering \\ and Surveying, Durban \\ University of Technology, \\ Durban, South Africa
}

\section{CORRESPONDENCE TO:}

Emmanuel Adewumi

\section{EMAIL:}

emmaadewumi@yahoo.com

\section{POSTAL ADDRESS:}

Department of Civil Engineering

and Surveying, Durban

University of Technology,

P0 Box 1334, Durban 4000,

South Africa

\section{KEYWORDS:}

vehicle manoeuvre; commuters; traffic congestion; dedicated

lane; Johannesburg

\section{HOW TO CITE:}

Adewumi E, Allopi D. Rea Vaya:

South Africa's first bus rapid

transit system. S Afr J Sci.

2013;109(7/8), Art. \#a0029, 3

pages. http://dx.doi.org/10.1590/

sajs.2013/a0029

(C) 2013. The Authors.

Published under a Creative

Commons Attribution Licence.
Today, both the public and private transport sectors are facing challenges as a result of an increase in vehicle ownership and the suburbanisation of both firms and residences in the world. In the past, public transport was focused mainly on central areas of cities where high population and employment densities enabled frequent services, high occupancy rates and many routes. As growth is spreading to suburban areas from the metropolitan area, imperative challenges arise for public transport: to increase service in order to better serve commuters and to integrate suburban service with metropolitan service. ${ }^{1}$ Public transport must be made more attractive and user friendly in relation to improved service, travel information, reliability, safety and the upgrade of infrastructure such as waiting stations. Cost is an important factor that influences the demand for public transport in relation to the time spent waiting, boarding and alighting from vehicles coupled with the risks and inconveniences involved in those actions. It has also been suggested that commuters and business users board the fastest and most direct routes. ${ }^{2}$ Here we comment on the performance and maintenance of the Rea Vaya system - South Africa's first bus rapid transit system - since its inception.

\section{Historical development of bus rapid transit}

The large-scale development of bus rapid transit (BRT) systems started in Curitiba (Brazil) in 1974, before which there were several smaller-scale projects. After the success of an effective BRT in Curitiba, other cities were inspired to develop similar systems. ${ }^{3}$ In the 1970 s, development of BRT systems was limited to the North and South American continents. In the late 1990s, the replication of the BRT concept gained momentum and BRT systems were opened in Quito, Ecuador (1996), Los Angeles, USA (1999) and Bogotá, Columbia (2000). ${ }^{4}$ The TransMilenio project in Bogotá started operation in 2000 and its success as a state-of-the-art BRT system drew attention from around the world. As of 2005, there were 70 such systems around the world, based on one definition of BRT. 5,6

\section{National operating subsidies}

Developing a business plan for a public transport system is difficult for any transport authority unless they know the rate of the operating subsidy that will be made available to them. At each metro or functional area, the existing level of subsidy should continue at the level currently allocated for bus subsidies. A judgement call must be made by the transport authority on which proportion of the subsidy will be allocated to catalytic initiative. In other words, the authority must plan for zero operating subsidy for the catalytic initiative as they have no control over the subsidy streams, which are in place because they applied to standard buses and rail. ${ }^{7}$

\section{Bus rapid transit systems in South Africa}

Commuters in the Gauteng Province have been using the BRT system called 'Rea Vaya', which means 'we are going'. It is the first of its kind in South Africa. Phase 1 of the BRT system, which linked Soweto to the centre of Johannesburg, came into effect on 30 August 2009. There are also functioning BRT systems in Cape Town, Port Elizabeth and Pretoria, and on-going implementation of such a system in Durban. ${ }^{8}$

\section{Johannesburg's bus rapid transit operation}

Rea Vaya has a capacity of up to 90 passengers on designated median lane trunk routes and currently conveys 16000 passengers per day. Complementary buses collect passengers at Rea Vaya stations on the trunk routes and operate on the kerbside of the lane. ${ }^{9}$

The South African cabinet appropriated public transport in an integrated way in March 2007. ${ }^{10}$ With funding at hand to address the issues of infrastructure and vehicles, they embarked on a solution for the severe traffic congestion and persistent mobility problems of the nearly 1.5 million transport users in the city. The first corridor spans through a 25-km trunk line with median lanes, 27 trunk stations and feeder routes that link the CBD and Soweto, which is one of the busiest commuter corridors in the city. ${ }^{11}$ (For the route map see http://www.reavaya.org.za/ images/stories/2009pdfs/startermap-27aug09.pdf)

\section{On-site assessment}

We assessed the performance of the system and its possible pros and cons on-site using a checklist (Table 1). The Rea Vaya BRT system makes use of a median bidirectional BRT lane configuration which is located in the middle of the roadway, as an exclusive right-of-way with pavement and lane markings, intersection road markings and stud separators $(10 \mathrm{~cm})$. The stud separators serve to separate the other traffic to avoid vehicle manoeuvre. It has distinctive branding in the form of markings on the vehicle that differentiate it from other public transport systems. The standard bus is fitted with low-emission technology, bi-fold doors at both sides and multiple entrances for boarding and alighting. 
Table 1: Checklist for the assessment of the Rea Vaya bus rapid transit system

\begin{tabular}{|c|c|}
\hline & Present \\
\hline \multicolumn{2}{|l|}{ Lane configuration } \\
\hline \multicolumn{2}{|l|}{ Basic separator cones } \\
\hline Pavement marking & $\sqrt{ }$ \\
\hline 10-cm separator blocks/studs & $\sqrt{ }$ \\
\hline \multicolumn{2}{|l|}{ 50-cm separator blocks/studs } \\
\hline \multicolumn{2}{|l|}{ Kerbside lane configuration } \\
\hline \multicolumn{2}{|l|}{ Segregated lane configuration } \\
\hline Median lane configuration & $\sqrt{ }$ \\
\hline Bus colouration/ road markings & \\
\hline Intersection roadmarking & $\sqrt{ }$ \\
\hline Lane marking & $\sqrt{ }$ \\
\hline Bus way with fully coloured way & \\
\hline Distinctive BRT identity and image & $\sqrt{ }$ \\
\hline Distinctive marketing identity for the system & $\sqrt{ }$ \\
\hline Landscaping & \\
\hline Cycle paths/footpaths & $\checkmark$ \\
\hline Tree planting and grassing & $\sqrt{ }$ (but minimal) \\
\hline Additional park or civic improvement & \\
\hline Integration with other modes at stations/terminals & \\
\hline Bicycle parking at stations/terminals & \\
\hline Formal taxi stands at stations/terminals & \\
\hline Car parking at stations/terminals & \\
\hline Intelligent Transportation System & \\
\hline Real-time information display & $\sqrt{ }$ \\
\hline Connection to the control room & $\sqrt{ }$ \\
\hline Audio announcements on BRT buses & \\
\hline Incorporation of schedule data into station electronic information systems & $\sqrt{ }$ \\
\hline Updates of schedules and maps at stops & $\sqrt{ }$ \\
\hline Adaptations of existing transit signal infrastructure & $\sqrt{ }$ \\
\hline Maps and information & \\
\hline Maps at station & $\sqrt{ }$ \\
\hline Information kiosk & $\sqrt{ }$ \\
\hline Station amenities & \\
\hline Air conditioning & \\
\hline Elevator for disabled & $\sqrt{ }$ \\
\hline Automatic doors & $\sqrt{ }$ \\
\hline CCTV/security & $\sqrt{ }$ \\
\hline Enhanced station environment & $\sqrt{ }$ \\
\hline Wheelchair accessible station & $\sqrt{ }$ \\
\hline Full weather protection on all station platforms & $\sqrt{ }$ \\
\hline Telephones & $\sqrt{ }$ \\
\hline Security & $\sqrt{ }$ \\
\hline Consistent pattern of station location, configuration and design & $\sqrt{ }$ \\
\hline Separate BRT, local bus, automobile and pedestrian movements in station design & \\
\hline Fare collection system & \\
\hline Smart card & $\sqrt{ }$ \\
\hline On-board fare collection & \\
\hline Pre-board fare collection and fare verification & $\sqrt{ }$ \\
\hline Flat fare type & $\sqrt{ }$ \\
\hline Zonal fare type & \\
\hline Distance-based type & \\
\hline Other & \\
\hline Convenient pedestrian and bicycle access to transit facilities & \\
\hline Bus stops are accessible to persons with disabilities & $\checkmark$ \\
\hline Wheelchair ramp access to the street at crosswalks or mid-blocks & $\sqrt{ }$ \\
\hline Stops accessible by sidewalk or pedestrian paths & $\sqrt{ }$ \\
\hline Bus stop shelters and/or benches & $\sqrt{ }$ \\
\hline Sufficient lighting & $\sqrt{ }$ \\
\hline Bus type & \\
\hline Low-emission vehicle technology & $\sqrt{ }$ \\
\hline One side doorway & \\
\hline Both sides doorway & $\sqrt{ }$ \\
\hline Standard bus type & $\sqrt{ }$ \\
\hline Articulated bus type & \\
\hline Bi-articulated bus type & \\
\hline Double-decker bus type & \\
\hline Boarding/alighting & \\
\hline Multiple-door boarding/alighting & $\sqrt{ }$ \\
\hline Single-door boarding/alighting & \\
\hline Door with ramp & $\sqrt{ }$ \\
\hline Door type & \\
\hline Swing door & \\
\hline Bi-fold door & $\sqrt{ }$ \\
\hline Plug & \\
\hline Pivot door & \\
\hline Sliding door & \\
\hline Other & \\
\hline Safety & \\
\hline Cleanliness & \\
\hline Accessibility & \\
\hline Reliability & \\
\hline Lack of intermodal coordination & \\
\hline Urban traffic congestion & \\
\hline Inability to meet service demand & \\
\hline Pedestrian crossing controlled by traffic light & \\
\hline Excessive bus-to-platform gaps at stations & \\
\hline
\end{tabular}


As the lane is located in the middle of the roadway, the stations are also constructed at the median of the roadway. Each station has maps, automatic doors on both sides of the station, an elevator for wheelchair accessibility, an enhanced environment, full weather protection on all platforms, telephones, security, CCTV and an information desk. The stations have a uniform configuration and design. In some places, the median of the road is decorated by planting of trees or grass and a footpath. The stations have branded temporary streamlined shelters with comfortable seats for the passengers to wait for the next available bus, CCTV, maps, security and real-time information displays. Realtime information displays and CCTV are installed at the stations as part of the Intelligent Transportation System (ITS) to improve passengers' convenience, speed, security and safety, and system reliability. The system makes use of CCTV for monitoring the operations of the buses using Automatic Vehicle Location, which is connected to the control room, and enables the update of schedules, both inside the bus and at the stations. Both smart card and off-board payments are accepted, but off-board payments, which are a flat rate, are more common. Pre-board fare collection and verification are exercised for those that are not using a smart card. The pedestrian crossings are controlled by traffic lights in most places. Existing transit signal infrastructure has been adopted where deemed suitable. The system is reportedly safe, clean, accessible, well coordinated between modes and able to meet service demand.

\section{Problems and challenges}

The ability to attract more customers, especially private car users, is important. The development of a robust business and financial model for continual maintenance of the existing system is a challenge. Continuous training for the owners and operators in the skills required to maintain the success of the system is necessary.

\section{Conclusion}

The median configuration of the Rea Vaya BRT system, which operates on a dedicated bus lane, offers improvement in travel time, reliability, safety and speed compared with other public transport systems and automobiles travelling in mixed-flow traffic lanes. A separate lane enables the system to have lower headways and accommodate higher peak period loads. When further combined with signal priority, delay is greatly minimised at intersections.

The BRT system is commuter friendly and cost effective over a long distance, compared with other public transport systems because it operates at a flat rate. Pedestrian safety, convenience and secure access to the facility for both the physically challenged and able commuters are provided. The installed ITS ensures passengers know the exact time and place to disembark, which is especially useful for those who are not familiar with their destination station.

\section{Recommendations}

To maintain a successful system, frequent maintenance is imperative. Should the need arise for BRT system diversification in Johannesburg, other lanes should be implemented using other forms of the BRT system and bicycle and car parking should be adopted at the main station. If there is further population intensification, articulated standard buses should be adopted. Smart cards should be used exclusively and will enable commuters to load more than a day's fare, depending on their financial capacity. Other modes of BRT, especially the segregated mode, should be employed for future BRT implementation. Although cost effective, the cost of the BRT system is justified by the high levels of efficiency, reliability and speed.

\section{References}

1. Pucker J, Hurth S. Verkehrsverbund: The success of regional public transport in Germany, Austria and Switzerland. Transport Policy. 1996;2(4):279-291. http://dx.doi.org/10.1016/0967-070X(95)00022-I

2. Conquest Research. Quality of interchanges. Report for London Transport Marketing. London: Conquest Research; 1997.

3. Matsumoto N. Analysis of policy processes to introduce bus rapid transit systems in Asian cities from the perspective of lesson-drawing: Cases of Jakarta, Seoul, and Beijing. Arlington, VA: Institute for Global Environmental Strategies; 2006. p. 1-20.

4. Ernst J. Initiating bus rapid transit in Jakarta, Indonesia. Transportation Research Record. 2005;19(3):20-26. http://dx.doi.org/10.3141/1903-03

5. Levinson H, Zimmerman S, Clinger J, Rutherford S, Smith RL, Cracknell J, et al. Transit Cooperative Research Program (TCRP) Report 90, Bus rapid transit : Case studies in bus rapid transit. Washington DC: Transportation Research Board; 2003.

6. Wright L. Bus rapid transit, sustainable transport: A sourcebook for policymakers in developing cities. Eschborn: Deutsche Gesellschaft fur Technische Zusammenarbeit; 2005.

7. Department of Transport. Public transport strategy. Pretoria: Department of Transport; 2007.

8. Thomas W. Bus rapid transit: A public transport solution for the BoP fact sheet. Stellenbosch: BoP Learning Lab, Stellenbosch University; 2010.

9. Department of Transport. Public transport action plan. Phase 1 (2007-2010): Catalytic integrated rapid public transport network projects 24. Pretoria: Department of Transport; 2007.

10. Cameron M. Press pack for the Johannesburg bus rapid transit system: Rea Vaya [document on the Internet]. c2010 [cited 2013 July 24]. Available from: http://www.illovoboulevard.com/pdfs/Jhb_BRT_System.pdf

11. Venter $C$. The lurch towards formalisation: Lessons from the implementation of BRT in Johannesburg, South Africa. Research in Transportation Economics. 2012;39(1):114-120. http://dx.doi.org/10.1016/j.retrec.2012.06.003 